\title{
Performance Study of Solar Air Heater with Baffled Duct
}

\author{
B.K. Maheshwari ${ }^{1}$, Rajendra Karwa ${ }^{2}$, R. Singhvi ${ }^{3}$, A. Goyal $^{4}$, \\ R.N. Kumawat ${ }^{5}$, A. Sharma ${ }^{6}$, R. Prajapat $^{7}$, D. Kumawat ${ }^{8}$, \\ M. Rankawat ${ }^{9}$, N. Bhardwaj ${ }^{10}$ \\ 1,3,4,5,6,7,9,10, Department of Mechanical Engineering, Faculty of Engineering \& Arch., J.N.V. University, \\ Jodhpur 342011, India \\ ${ }^{2}$ JIET School of Engineering \& Technology, Mogra, N.H. 65, New Pali Road, Jodhpur 342002, India
}

\begin{abstract}
The paper presents results of an experimental performance study of a solar air heater having perforated baffles (baffles open area ratio of 46.8\%) on the air flow side of the absorber plate. A direct performance comparison of the baffled duct and smooth duct solar air heaters shows that the thermal efficiency of the baffled duct solar air heater is about 22-33\% higher than the smooth duct solar air heater; highest thermal performance advantage is at the lowest flow rate. The enhancement is attributed to the heat transfer enhancement due to the perforated baffles on the absorber plate and reduction in the mean absorber plate temperature. The pumping power requirement has been found to be only a small fraction of the heat collection rate.
\end{abstract}

Key Words: Solar air heater, baffled duct, thermal efficiency, pumping power

\section{Introduction}

The flat plate collector is heart of solar thermal systems designed for operation in the low to medium temperature range of slightly above the ambient to about $100^{\circ} \mathrm{C}$. In general, the thermal efficiency of a flat plate solar air heater is lower than that of a water heating collector because of a low value of heat transfer coefficient between the absorber plate and the air flowing through the collector duct, which leads to a high temperature of the absorber plate and greater heat loss. Roughness elements in the form of ribs (small height projections), baffles (thin elements of greater heights) or blocks (thick elements) have been employed to enhance heat transfer in gas turbine blade cooling channels and solar air heaters. While the use of solid roughness elements or baffles results in significant heat transfer enhancement, the associated increase in pressure drop is of serious concern. Hot zones develop in the wake of these elements because of the re-circulating flow. This leads to a lower heat transfer rate from the zone behind the elements. Attempts have been made to overcome these adverse effects by development of different designs of the ribs. Another way of improving the heat transfer rate is to employ attachments with perforations or detached ribs. The perforated baffles or blocks allow a part of the flow to pass through the perforations and hence the hot zone and form drag are reduced [1-5]. Thus the perforated elements enhance the heat transfer rate with lower pressure loss penalty.

Karwa et al. [5] studied the thermo-hydraulic effectiveness of open area ratio (the ratio of the area of the holes to the baffle frontal area) of the baffles. Their experimental study on heat transfer and friction in an asymmetrically heated rectangular duct with solid or perforated baffles installed at a pitch to baffle height ratio of 29 showed an enhancement of 73.7-82.7\% in the Nusselt number for the duct with solid baffles over a smooth duct, and from $60.6-62.9 \%$ to $45.0-49.7 \%$ for the perforated baffles (the enhancement in the Nusselt number decreasing with the increase in the open area ratio). The friction factor for the solid baffles was found to be 9.611.1 times of the smooth duct, which decreased significantly for the perforated baffles with the increase in the open area ratio; it was only 2.3-3.0 times for the baffles with an open area ratio of $46.8 \%$. The baffles with the highest open area ratio gave the best performance compared to a smooth duct at equal pumping power. Hwang and Liou [3] found that the Nusselt number ratio increased monotonously with the decrease in pitch to height ratio in the case of perforated ribs.

From the literature study, it has been inferred that the thermo-hydraulic performance of perforated baffles attached to the absorber plate of a solar air heater at a pitch less than 29 is worth investigation.

In the present study, perforated baffles of Karwa et al. [5] with an open area ratio of $46.8 \%$ have been used on the airflow side of the absorber plate of the solar air heater as shown in Fig. 1(a), because their experimental study has shown the thermo-hydraulic performance advantage of such baffles in an asymmetrically heated rectangular duct whose boundary conditions confirm closely to those of a solar air heater.

II. Experimental Setup

An experimental test facility, as reported in an earlier publication [6], has been designed and fabricated as per ASHRAE Standard 93-77 [7] for the testing of solar collectors, which works in an open loop mode. It 
consists of two parallel ducts (each $300 \mathrm{~mm}$ in width) with entrance, test and exit sections, a blower, control valves, and provision for temperature, flow and pressure drop measurements. The parallel ducts are made of good quality plywood and wooden boards with a very smooth surface finish for the air flow ducts. Each duct is $2.88 \mathrm{~m}$ long with $1.65 \mathrm{~m}$ long test section. Duct height has been kept fixed at $38.4 \mathrm{~mm}$. The test section of one of the ducts carries the absorber plate with baffles at the top, while the other duct carries a smooth surfaced absorber plate. The sun facing sides of both the absorber plates are smooth and blackened. Glass covers of $4 \mathrm{~mm}$ thickness have been placed over the absorber plates at a height of $60 \mathrm{~mm}$. The top side of entry and exit length of both ducts are covered with smooth faced plywood.

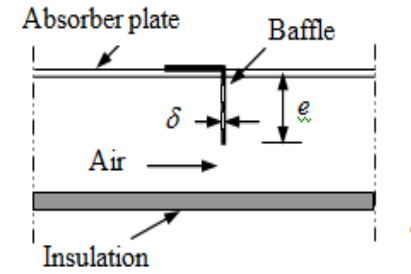

(a)

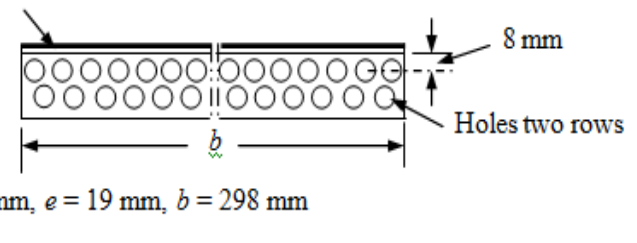

(b)

\section{Fig. 1 (a) Absorber plate with baffles $\quad$ (b) A perforated baffle.}

This parallel ducts test facility allows a direct comparison of the performance of the baffled and smooth duct collectors. The baffled duct consists of $3.25 \mathrm{~mm}$ thick aluminium absorber plate with perforated baffles with an open area ratio of $46.8 \%$ installed transverse to the flow at a pitch to baffle height ratio of about 14.5 , refer Fig. 1. Table 1 gives the details of the baffles employed in the study and other experimental conditions.

Calibrated copper-constantan thermocouples $(0.36 \mathrm{~mm}$ diameter $)$ have been employed for various temperature measurements. The thermocouples have been fixed with epoxy in $3 \mathrm{~mm}$ diameter holes drilled about $2.5 \mathrm{~mm}$ deep in the sun side of the absorber plates. Thermocouples have been affixed at 9 and 12 axial locations in smooth and baffled absorber plates, respectively, as depicted in Fig. 2. Three thermocouples are placed in the temperature measuring section after the mixing section to measure the temperature of the outlet air. A thermocouple has been placed midway in the entry section of each duct to measure the inlet air temperature.

Pressure taps, located along the axial center line of the smooth lower walls of the test sections, measure the pressure drop across the test section using a null balance type micro-manometer having a least count of 0.02 $\mathrm{mm}$. Inclined U-tube manometers have been used to measure the pressure drop across the orifice plates.

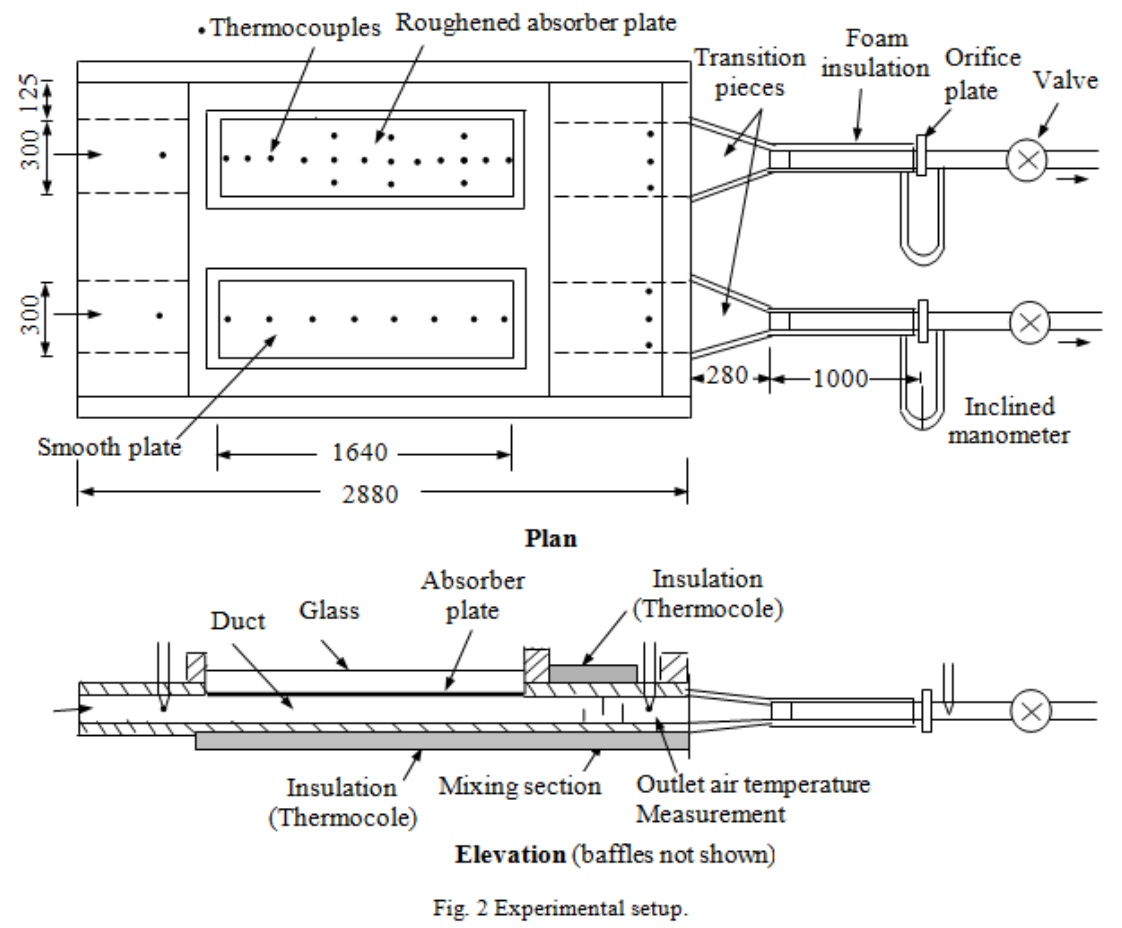

A $100 \mathrm{~mm}$ long mixing section with baffles provides uniform temperature of the exit air in the temperature measuring section. The exit end of each duct is connected through a rectangular to circular transition piece to a $68 \mathrm{~mm}$ inner diameter G.I. pipe carrying orifice plate assembly; orifice throat diameter is 38 
$\mathrm{mm}$. The other end of the each pipe is connected through control valve to the suction of a $10 \mathrm{HP}$ blower through a Y-section (not shown in the figure).

Adequate thermal insulation ( $50 \mathrm{~mm}$ thermocole or foam insulation) has been provided as shown in the figure. All joints were properly sealed with $\mathrm{NC}$ or window putty.

A precision solarimeter has been used for the measurement of the solar radiation on the collector plane. The wind velocity just above the collector plane has been measured by a wind speed meter. The ambient temperature has been assumed to be equal to the air inlet temperature. The set-up was installed horizontal on the roof top. The test was started at 9.30 am and observations were made every 30 min between 10.30 am and $2 \mathrm{pm}$.

\section{Data Reduction}

The mean plate temperature $T_{\mathrm{p}}$ is the simple mean of temperature readings noted at various points along the axial length of the absorber plate, i.e.,

$$
T_{\mathrm{p}}=(1 / n)\left[T_{1}+T_{2}+\ldots \ldots+T_{\mathrm{n}}\right]
$$

where $n$ is the number of axial locations of the thermocouples on the absorber plate surface.

The mean air temperature $T_{\mathrm{m}}$ is taken as arithmetic mean of the measured inlet and outlet air temperature values, i.e.

$$
T_{\mathrm{m}}=\left(T_{\mathrm{i}}+T_{\mathrm{o}}\right) / 2
$$

The mass flow rate of air is determined from the measured pressure drop across the orifice plate:

$$
\dot{m}=c_{\mathrm{d}} A_{\mathrm{o}} \sqrt{ }\left(2 \Delta p_{\mathrm{o}} p_{\mathrm{a}} / R T_{\mathrm{o}}\right)
$$

Mass flow rate per unit area of the absorber plate $G$ is calculated from:

$$
G=\dot{m} / A
$$

where $A=W L$ is the absorber plate area.

The Reynolds number of the flow of air in the duct is calculated from:

$$
\operatorname{Re}=G_{1} D_{\mathrm{h}} / \mu
$$

where $G_{1}=\dot{m} /(W H)$ is mass velocity of air in the duct and $D_{\mathrm{h}}=4 W H /[2(W+H)]$ is the hydraulic diameter.

Useful heat gain $\dot{Q}$ is the rate of heat transfer to the air from the heated absorber plate:

$\dot{Q}=\dot{m} c_{\mathrm{p}}\left(T_{\mathrm{o}}-T_{\mathrm{i}}\right)$

Table 1 Baffles and test duct details, and experimental conditions

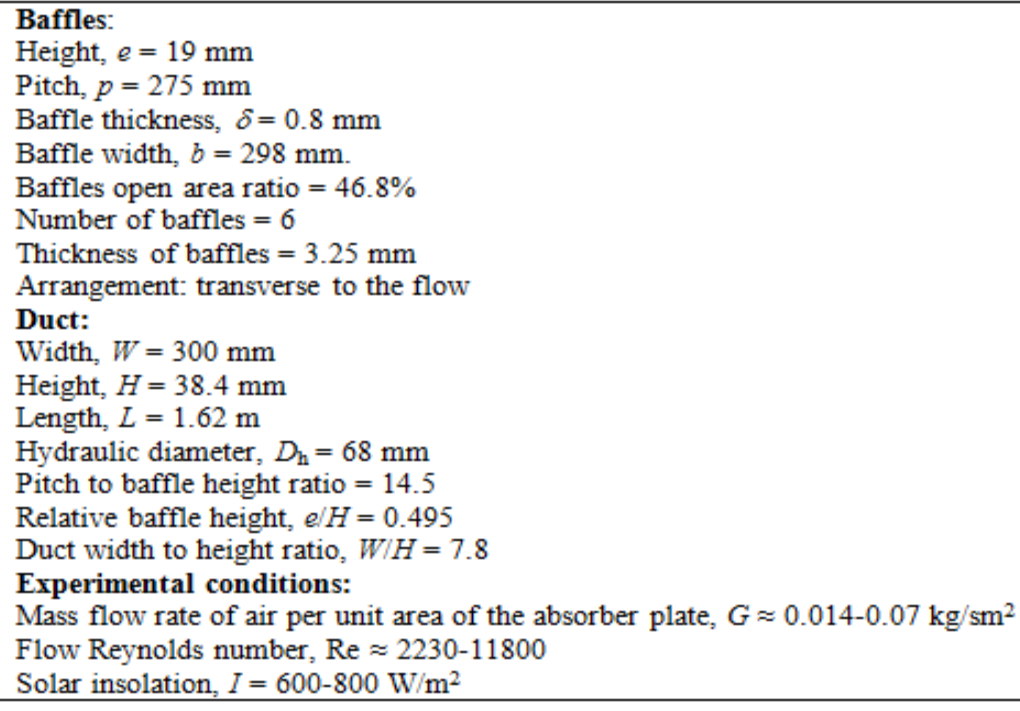


Thermal efficiency of the collector is a ratio of the useful heat gain to the incident solar radiation on the collector aperture area

$$
\eta=\dot{Q} /\left(A_{\mathrm{a}} I\right)
$$

From the known values of pressure drop $\Delta p_{\mathrm{d}}$ across the test section and the mass flow rate, the pumping power is obtained from:

$$
P=(\dot{m} / \rho) \Delta p_{\mathrm{d}}
$$

From the analysis of uncertainties in the recording of various experimental data [8] the uncertainties (odds of 20:1) in the values of various parameters have been estimated as [6]

Mass flow rate per unit area of absorber plate, $G= \pm 1.6 \%$

Heat collection rate, $Q= \pm 3.8 \%$

Thermal efficiency, $\eta= \pm 4.9 \%$

Pumping power, $P= \pm 4.3 \%$.

\section{Results And Discussion}

In Figure 2, the enhancement ratio, ratio of thermal efficiencies of solar air heaters with perforated baffles and smooth duct is plotted against the air mass flow rate per unit area of the absorber plate. A thermal performance advantage of the order of $22-33 \%$ over the smooth duct solar air heater can be seen, which can be attributed to the heat transfer enhancement due to the baffles. The highest advantage is at the lowest flow rate of the study. The thermal efficiency of the baffled duct solar air is 40-84\% (Fig. 3); increasing with the flow rate because an increase in the flow velocity results in the increase in the heat transfer coefficient.

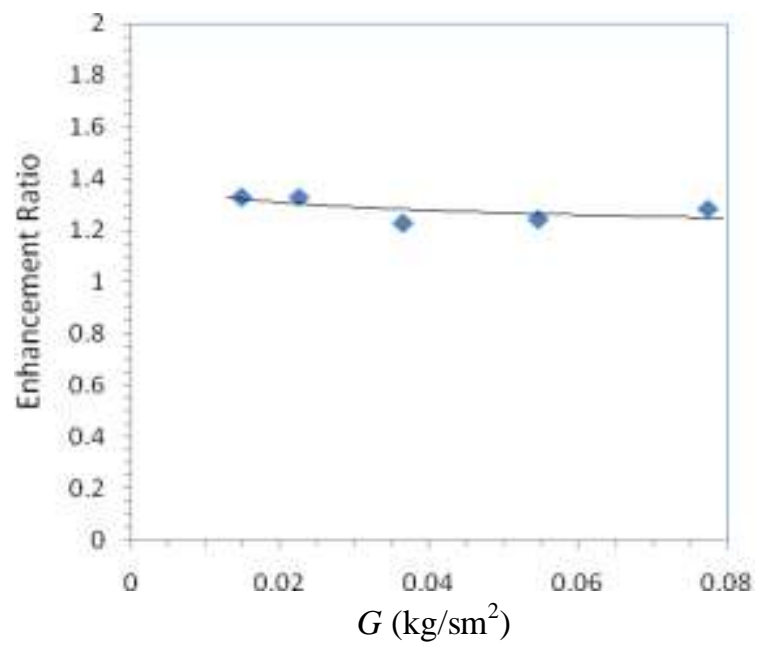

Fig. 3 Thermal efficiency versus the flow rate per unit area of absorber plate

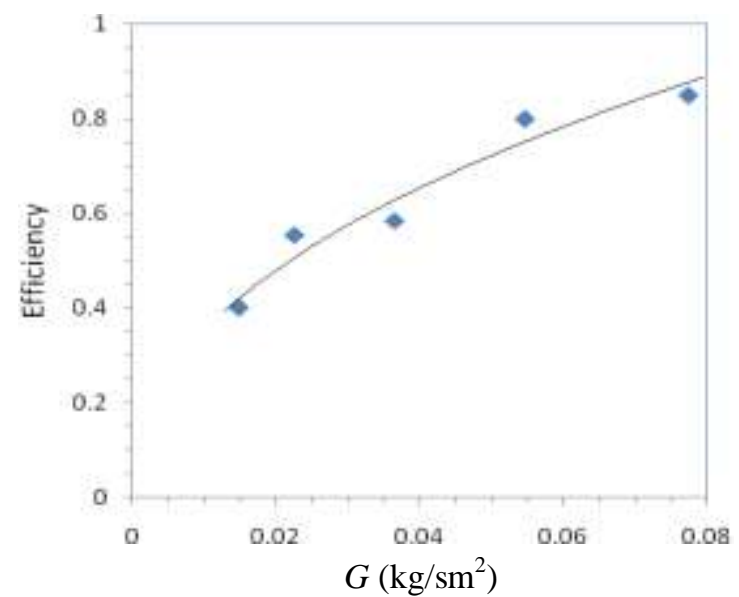

Fig. 4 Thermal efficiency of baffled duct solar air heater 
The mean temperature of the baffled absorber plate over the ambient temperature $\left(T_{\mathrm{p}}-T_{\mathrm{a}}\right)$ has been found to be lower by $4-14^{\circ} \mathrm{C}$ as compared to the smooth duct air heater. Thus, both the increase in the heat collection rate due to the enhancement in the heat transfer coefficient and decrease in the heat loss from the collector due to the lower working temperature of the absorber plate lead to an increase in the thermal efficiency of the collector.

The pumping power requirement has been found to be quite insignificant and, hence, the perforated baffled duct solar air heaters are thermo-hydraulically advantageous and can be employed for applications involving mass flow rate per unit area of the absorber plate of $0.014-0.07 \mathrm{kgs}^{-1} \mathrm{~m}^{-2}$.

\section{Conclusions}

An experimental study on performance of a solar air heater having perforated baffles on the air flow side of the absorber plate has been made for air mass flow rate of about $0.014-0.07 \mathrm{~kg} / \mathrm{s} \mathrm{per}^{2}$ of the absorber plate area. A direct performance comparison of the performance of the solar air heater with baffled duct with the smooth duct solar air heater shows that

1. The thermal efficiency of the baffled duct solar air heater is about 22-33\% higher than the smooth duct solar air heater; highest thermal performance advantage is at the lowest flow rate.

2. The heat transfer enhancement due to the baffles increases the heat collection rate and reduces the mean temperature of the baffled absorber plate by $4-14^{\circ} \mathrm{C}$ as compared to the smooth one.

3. The pumping power requirement is found to be a small fraction of the heat collection rate in the range of the present study.

\section{Nomenclature}

A absorber plate area

$A_{\mathrm{a}} \quad$ collector aperture area

$A_{\mathrm{o}} \quad$ orifice throat area

$c_{\mathrm{d}} \quad$ coefficient of discharge

$c_{\mathrm{p}} \quad$ specific heat

$D_{\mathrm{h}} \quad$ hydraulic diameter of the duct

$e \quad$ height of baffle

$e / H$ relative baffle height

$g \quad$ acceleration due to gravity

$G$ mass flow rate per unit area of the absorber plate

$G_{1} \quad$ mass velocity

$H$ height of duct

$\eta \quad$ thermal efficiency

I solar insolation

$L \quad$ length of test section

$\begin{array}{ll}m & \text { mass flow rate } \\ \mu & \text { viscosity of air } \\ p & \text { pitch } \\ P & \text { pumping power } \\ p_{\mathrm{a}} & \text { ambient pressure } \\ \Delta p_{\mathrm{d}} & \text { pressure drop across duct } \\ \Delta p_{\mathrm{o}} & \text { pressure drop across orifice plate } \\ p / e & \text { relative roughness pitch } \\ Q & \text { useful heat gain } \\ R & \text { gas constant } \\ \mathrm{Re} & \text { flow Reynolds number } \\ \rho & \text { density of air } \\ T_{\mathrm{i}} & \text { inlet air temperature } \\ T_{\mathrm{o}} & \text { outlet air temperature } \\ T_{\mathrm{m}} & \text { mean air temperature } \\ T_{\mathrm{P}} & \text { mean plate temperature } \\ W & \text { width of duct }\end{array}$

\section{References}

[1] J.-J. Hwang, T.Y. Lia, and T.-M. Liou, Effect of fence thickness on pressure drop and heat transfer in a perforated-fenced channel, International Journal of Heat and Mass Transfer, 41(4-5), 1998, 811-816.

[2] J.-J. Hwang and T.-M Liou, Augmented heat transfer in a rectangular channel with permeable ribs mounted on the wall, ASME Journal of Heat Transfer, 116, 1994, 912-920.

[3] J.-J. Hwang and T.-M Liou, Heat transfer in a rectangular channel with perforated turbulence promoters using holographic interferometry measurement, International Journal of Heat and Mass Transfer, 38(17), 1995, 3197-3207.

[4] O.N. Sara, T. Pekdemir, S. Yapici, and M. Yilmaz, Heat transfer enhancement in a channel flow with perforated rectangular blocks, International Journal of Heat and Fluid Flow, 22, 2001, 509-518.

[5] Rajendra Karwa, B.K. Maheshwari, and Nitin Karwa, Experimental study of heat transfer enhancement in an asymmetrically heated rectangular duct with perforated baffles, International Communication in Heat and Mass Transfer, 32, 2005, $275-284$.

[6] B.K. Maheshwari, Rajendra Karwa, and S.K. Gharai, Performance study of solar air heater having absorber plate with half perforated baffles, ISRN Renewable Energy, 2011, Article ID 634025, doi:10.5402/2011/634025.

[7] ASHRAE Standard 93-77, Methods of testing to determine the thermal performance of solar collectors, New York, 1977.

[8] S.J. Kline, and F.A. McClintock, Describing uncertainties in single sample experiments, Mechanical Engineering, 75, 1953, 3-8. 